\section{COCAINE POISONING.:}

BY

CHUNILAL BOSE, M.B., F.C.S., A CDFNICAL EXAMTNER TO THE GOTERNMEXT OF BENGAL; FELION OF

Not many year's ago cocaine was a drug hardly known to the people of India outside the medical profession, and now, sad to reflect, it has taken a vigorous hold of a certain class of people in this country both in town and village. In Calcutta, despite the vigilance of the excise authorities, and notwithstanding the stringent measures lirected by the Government against the possession and the sale of this substance by unlicensed persons, there is reason to believe that the cocaine habit has much increased and is rapidly spreading. Moreover, it is perhaps safe to say that a considerable proportion of the crimes committed in this city may be traced to the utter moral depravity which follows the habitual use of cocaine. The daily papers are full of the reports of raids on cocaine dens and of cocaine seizures, and the references made to the Chemical Examiner in connexion with the illicit import and the unlawful possession of cocaine are rapidly and progressively on the increase, as may be scen from the figures given below, compiled from the annual reports of the Chemical Examiner's Department, Bengal, for the last four years :

\begin{tabular}{|c|c|c|c|}
\hline \multicolumn{3}{|c|}{ Year. } & $\begin{array}{l}\text { Number of Samples of Cocaine Seized } \\
\text { and Sent for Examination. }\end{array}$ \\
\hline 1908 & ... & ... & 125 \\
\hline 1909 & ... & $\ldots$ & 243 \\
\hline 1910 & $\ldots \quad \ldots$ & $\ldots$ & 621 \\
\hline 1911 & ... & $\ldots$ & 2,138 \\
\hline
\end{tabular}

Although the cocaine habit has been described by Erlenmeyer as the third scourge of humanity, the two first being alcohol and opium, yet in some respects cocainomania is more disastrous in its effect on the moral, intellectual, and the physical well-being of the subject. Professor Berkeley, of the Johns Hopkins Uuiversity, has observed that he would trust a cocaine debauchee even less than he would a morphinomaniac, stating as his reason that the moral rectitude and the will power of a ocaine eater always suffer more severely. In Taylor"s l'rinciples and Practice of Medical Jurisprulence, it is said, referring to chronic cases, that,

like morphia, the habit of cocaine seems to sap the moral tibre of its devotees, so that they become reci'ess of everything in their efforts to obtain their dose-lying, cheating, tealing, notbing comes amiss to them, so that their craving is satisfied.

Dr. A. H. Brundage, Professor of Toxicology in the Brooklyn College of Pliarmacy, remarks that the cocaine liabit

is the most seductive, dangerous and mentally, physically and morally destructive of all the drug habits. Cocaine fascinates by the promptness with which it relieves all sense of exhaus tion, dispels gloom, and exhilarates, producing a sense of happiness and well-being which transports at once to a longed-fo Clysium. Primarily the after-effects are scarcely perceptible, but through continual indulgence an intense craving for the ?rug or its effects is produced.

It is the utter banishment of gloom and the delightful sense of bien.être, which together are directly responsible for the intense craving, characteristic of the habit and proluctive of the physical, mental and moral degradation and depravity which ensue.

Professor Berkeley reports that the body weight sinks rapidly, even one-fifth to one-third of it being lost within a fow weeks.

Dr. Kailas Chandra Bose, Rai Bahadur, C.I.E., in the March number of the Indian Medical Gazette, 1902, recorded several cases of the habitual use of cocaine, and summarized the principal symptoms nojiced. These were headache, anorexia, emaciation, insomnia, a blackening of the tongue and teeth, dilated pupils, rapid and feeble, sometimes irregular or intermittent pulse, fainting attacks,

Read at a clinical meeting of the Calcutta Hedical Club. November, hallucinations, incoherent speech and convulsions. In one case there was obstinate diarrhoea, and in another there were symptoms of acute mania.

\section{Prognosis.}

Professor Berkeley observes that the prognosis is "most gloomy," for,

even though the patient recorer from one attack, he very frequently relapses into his evil habits. In the most favourable cases there remains an extraordinary weakness of the will power, with accentuated tendencr to relieve the phrsical and psychical languor by substituting for the cecaine alcohol, morphine, and other nervines in large quantities.

Dose.

The medicinal dose of the lydrochlorate of cocaine is $\frac{1}{5}$ to $\frac{1}{2}$ grain. The minimum fatal quantities on record are $\frac{2}{3}$ grain hypodermically, 12 to 15 grains by the mouth, and 22 grains by rectal injection.

A few cases have been recorded in European practice in which the drug either proved fatal or produced very severe symptoms when it was injected hypodermically or passed into the natural cavities prior to a surgical operation or administered internally. In one case the injection of $3 \frac{1}{2}$ grains into the breast of an adult woman was immediately followed by epilep. tiform convulsions, and in twenty minutes by death. In another instance, the hypodermic use of $\frac{2}{3}$ grain in a woman, aged 71 , proved fatal in five hours. In the Pharmaceutical Journal, 1886 (iii, 16, 721), a case is recorded in which the hypodermic injection of $\frac{1}{20}$ grain caused dangerous symptoms in a girl aged 12 years. On November 2nd, 1895, a case was reported in the Lancet, in which 2 drachms of a 10 per cent. solution of cocaine (representing 12 grains of the drug) taken internally for the relief of a toothache caused death in twenty minutes, with epileptiform convulsions. In another case $\mathbf{x}^{1} \bar{\sigma}$ grain applied locally to the conjunctiva gave rise to dangerous symptoms; while in still another instance acute nianifestations followed the injection of half a drachm of a 10 per cent. solution - that is, grains iij-into the urethra. A rectal injection of 22 grains of cocaine has been productive of death.

The prominent symptoms in all these acute cases of poisoning consisted of dryness and numbness of the mouth and throat, vertigo, dyspnoea, failure of the special senses of sight, hearing, and smell, numbness of the extremities, rapid and feeble, sometimes irregular or intermittent pulse, muscular tremors, a staggering gait, dilated pupils, epileptiform, sometimes tetanoid convulsions, cyanosis, and insensibility.

The practical lesson to be learnt from cases like these is the extreme care which is necessary in administering the drug for the production of local anaesthesia in dental practice and surgical cases.

No case has yet been recorded in Indian medical practice, so far as I have been able to ascertain, of acute cocaine poisoning with a fatal result. In the twenty-seven years during which I have been connected with the Chemical Examiner's Department in Bengal, I have not had a single case of fatal cocaine poisoning referred to me, except the three which I am about to recount, all of which occurred within the past six months. Not only does this fact appear to indicate that the drug is rery easily procurable by the common people, in spite of the strict regulations against it, but it also seems reasonable to infer that the people are getting to be more familiar with the uses to which the substance can be put.

CASE I.

B. D., a Hindu male, aged about 23 years, a resilent of Cal. cutta, and by occupation a pressman, was addicted to alcohol and to cocaine. On May 28th, 1912, he played cards with his friends up to a late hour of the night and distributed pan (betel) with cocaine to his companions, taking the largest share himself. He left the place soon after, and at 2.30 a.m. on May 29th, self. He left the place soon after, and at 2.30 a.m. On May 29th, he was found lying unconscious and groaning at a neighbour's to hospital, but died on the way there.

\section{Post-mortem Appearanecs.}

Body poorly nourished; rigor mortis present; pupils normal. The lungs, the kidneys, the brain and its membranes and the mucous membrane of the stomach were found congested. The stomach contained about $2 \mathrm{oz}$. of recently taken food without any special odour. 
Chemical Analysis.

The viscera of the deceased, and a small quantity of urine found in his bladder were forwarded to me for chemical analysis, and I detected cocaine in both. I could detect no other poison in the viscera. The dose taken by the deceased could not in the viscera.

$$
\text { CASE II. }
$$

K., a Hindu female, aged about 28 years, a woman of the town, was in the habit of taking cocaine. She left home at about 1.30 a.m. on August 29th, 1912, and returned at 6.30 a.m. a few hours later. She was seen to be staggering while washing her mouth at a hydrant hard by. Very soon afterwards she lay down, became unconscious, and in a few minutes she died.

$$
\text { Post-mortem Appearances. }
$$

Body fairly nourished; rigor mortis present; pupils slightly contracted; there were no marks of violence on the body. The brain and its membranes, the liver, the spleen, the kidneys, the ovaries, the bladder, and the mucous membrane of the stomach were found congested. The right heart was dilated, and contained dark fluid blood. The stomach contained about $3 \mathrm{oz}$. of recently taken vegetable food without special odour.

\section{Chemical Analysis.}

The viscera in the case were sent to me for chemical analysis and $I$ detected a marked quantity of cocaine in them. I detected no other poison in the viscera. Neither the dose taken nor the fatal period could be ascertained in this case.

$$
\text { CASE III. }
$$

M. K., a Hindu female, aged about 20 years, lived with her husband in Calcutta. On October 17th, 1912, she visited her sister-in-law, L. K., and at about 7 p.m. on the following day she sister-in-law, L. K., and at about 7 p.m. on the following day she offered $L$. some white powder which she believed to be a
specific remedy for acidity and indigestion. They each took some of the powder, and within half an hour they became ill some of the powder, and within half an hour they became ill
and then unconscious. M. died soon after, but $L$. regained and then unconscious. M. died soon after, but L. regained Medical College Hospital.

\section{Post-mortem Appearances.}

Rigor mortis present; body well-nourished; pupils slightly contracted; there were no external marks of violence visible. The brain, the meninges, and the lungs were highly congested. The liver, the spleen, the kidneys, the larynx, and the trachea were also found congested. The stomach contained about $9 \mathrm{oz}$. of sour-smelling food.

\section{Chemical Analysis.}

The viscera were forwarded to me for chemical analysis and I detected cocaine in them. There was no other poison present in the viscera. The dose taken by the deceased could not be ascertained, but death took place in this case in about half an hour.

$$
\text { CASE IV. }
$$

The case of L. K., sister-in-law of victim No. III, constitutes a fourth case, but it did not terminate fatally. The dose taken rendered the patient unconscious in half an hour, and kept her so for four hours. Her pulse and respiration are said to have been normal during her stay in hospital and her pupils slightly dilated.

The stomach washings were sent to me for chemical analysis, and I detected cocaine in them but no other poison.

\section{Method of Detection.}

In all these cases I extracted cocaine by Stas's process. The ethereal extract, on being applied to the tongue, produced very marked anaesthesia. When this was dissolved in dilute hydrochloric acid and evaporated to dryness in a water bati it left a residue which gave well-marked reactions with the principal alkaloidal reagents.

The hydrochlorate thus obtained, when treated with a solution of picric acid, gave a copious precipitate which under the microscope showed the usual long needles arranged in starshaped bundles.

A fresh portion of the residue treated with a drop of a strong solution of alum and next with a drop of potassium permanganate solution yielded a deep reddish-brown precipitate. The latter, under the microscope, showed the characteristic rectangular plates.

Another portion of the residue was treated with strong nitric acid and evaporated to dryness. The addition to it at this stage of a few drops of an alcoholic solution of potash caused the characteristic peppermint-like odour of ethyl benzoate to evolve.

A 5 per cent. solution of chromic acid added to a solution of the hydrochlorate produced an abundant precipitate which disappeared on shaking. The subsequent addition of a drop of strong hydrochloric acid caused a copious yellow precipitate.

\section{Treatment.}

In acute cases the stomach pump should be used, as the anaesthetic effect of the drug on the mucous membrane of the stomach might interfere with the action of an emetic. Hot coffee and stimulants, such as brandy, ether, and ammonia, should be freely given, and hypodermic injections of ether, strychnine, and digitalis might be.desirable. In convulsions I may say that chloroform is useful. Morphine appears to possess an antidotal action against cocaine, and it might be used hypodermically. Inhalation of amy nitrite has also been recommended. Perfect rest in a lying position should be enjoined in all cases.

My best thanks are due to Captain St. John Moses, M.D., D.Sc., F.R.C.S., F.R.S.E., I.M.S., police surgeon of Calcutta, for kindly supplying me with the notes of the post-mortem examination of the three fatal cases and for generally revising this paper.

\section{AN EXPERIMENT TO ILLUSTRATE THE EFFEC'T OF SIZE OF POPULATION ON THE RATE OF SELECTION OF NEW BACTERIAL RACES.}

By W. J. PENFOLD, ASSISTANT BACTERIOLOGIST, LISTER INSTITUTE, LONDON.

IN the course of a research into the question of the selection of a variant of $B$. tyyhosus in respect of dulcite-fermenting power, the follc wing experiment was designed with the view of ascertaining whether the bulk of the fluid medium in which the organism was grown had any marked influence on the rate of selection of the new race.

A set of nine beakers, each beaker being $5 \frac{1}{2} \mathrm{~cm}$. in diameter, and a set of nine test tubes, each tube being $1 \mathrm{~cm}$. in diameter, were filled to the depth of $1 \mathrm{in}$. witl the same sample of dulcite peptone water of the following composition, and containing litmus as indicator :

$\begin{array}{lccccc}\text { Peptone (Witte) } & \ldots & \ldots & \ldots & 20 \text { grams } \\ \text { Dulcite } & \ldots & \ldots & \ldots & \ldots & 5 \\ \text { Salt ... } & \ldots & \ldots & \ldots & \ldots & 5 \\ \text { Water } & \ldots & \ldots & \ldots & \ldots & 1 \text { litre }\end{array}$

The dulcite-peptone water was rendered faintly alkaline to litmus and sterilized by steaming on three successive days. The tubes and beakers were of the same height, so that the condition of aëration of the medium was strictly similar in each series. This precaution is necessary, as it is well known that alkali formation from the peptone is greatly favoured by free access of air. Each member of these two series was inoculated with the same quantity of B. typhosus broth. The strain selected for this purpose was one which, from previous testing, was known to acquire the power of fermenting dulcite more slowly than the majority of strains. All the cultures were incubated at $37^{\circ} \mathrm{C}$.

The time taken to produce acidity in the original beakers and tubes is given in Table I, and it will be noted that no test-tube culture became acid during the period of observation (twenty-six days).

After eight days' growth subcultures were made from each tube and each beaker into 6 c.cm. quantities of dulcite-peptone water contained in ordinary test tubes. The times taken to produce acidity in these subcultures are given in Table II. Again no subculture from tho original test tubes became acid.

After a further period of seven days-that is, fifteen days from the commencement of the experimentcultures were again made from the original beakers and tubes into ordinary $6 \mathrm{c.cm}$. quantities of dulcite broth. The times required for appearance of acidity are indicated in Table III.

These various tables show that a fermenting race is much more quickiy produced by growth of the organism in large quantities of culture medium than in small quantities. If the original small tubes be inoculated with small doses of $B$. typhosus broth and the beakers with large doses, the sizes of these doses being related to eacl other as the volumes of the dulcite broths to be inoculated, the fermenting race is again found to arise more quickly in the large quantities.

The original small tubes never developed an acid reaction, and their subcultures likewise did not, within the limits of observation. The large cultures in beakers developed an acid reaction in every case by the fifteentl day. Their first subcultures showed three with a full acid reaction by the tenth day. In the second subcultures from the original beakers nine became fully acid in reaction by the sixth day.

The experiment above detailed was led up to by a pre liminary experiment performed with a $B$. typhosus strain which was known to acquire the power of fermenting 